\title{
PEMANFAATAN KARAKTERISTIK GETARAN DALAM MENENTUKAN KONSTRUKSI SAMBUNGAN KAPAL KAYU YANG TEPAT DAN BERSESUAIAN DENGAN KARAKTER MESIN
}

\author{
R. P. Soumokil $1^{1, *}$ \\ 1Jurusan Teknik Perkapalan Fakultas Teknik Universitas Pattimura, Ambon 97234 \\ *ruth.soumokil@fatek.unpatti.ac.id
}

\begin{abstract}
Abstrak. Sumber eksitasi utama pada kapal kayu tradisional bermesin adalah getaran mesin induk. Struktur dirancang untuk dapat menahan beban dari gaya-gaya yang bekerja padanya. Tipe mesin yang digunakan di Maluku kebanyakan adalah tipe mesin dari China dikarenakan harganya yang lebih terjangkau. Agar getaran mesin induk dapat terdistribusi merata, maka karakteristik konstruksi di daerah sambungan harus diketahui agar transmisi bisa direkayasa dan resonansi pada titik tertentu dapat dihindari. Penelitian ini bertujuan untuk menganalisa getaran pada daerah konstruksi kapal kayu dengan sumber eksitasi yang berbeda. Sumber eksitasi berasal dari dua mesin yang berbeda yang dipasang pada kapal dengan ukuran yang sama. Penggunaan dua mesin berbeda bertujuan agar analisis mampu merekomendasikan sambungan yang sesuai dengan performa masing-masing mesin melalui besarnya amplitude yang terjadi di titik-titik sambungan. Hasil penelitian menunjukkan bahwa mesin Dong Feng memiliki nilai amplitude terkecil masih di 0,078 $\mathrm{mm}$ pada arah serat Tangensial, masih di atas batas amplitude yang diijinkan yaitu $0,039 \mathrm{~mm}$ untuk arah getaran horisontal. Amplitude yang dihasilkan akibat penggunaan mesin Dong Feng akan lebih kecil jika menggunakan sambungan model III, takik lurus berkait, dengan arah serat radial, sedangkan mesin Yanmar akan lebih baik jika menggunakan sambungan model II, dengan arah serat tangensial.
\end{abstract}

Kata kunci: karakteristik getaran, eksitasi, sambungan, resonansi, amplitudo

\begin{abstract}
The main source of excitation on traditional wooden motorized vessels is the vibration of the main engine. The structure is designed to be able to withstand the burden of the forces acting on it. The type of engine used in Maluku is mostly from China due to its more affordable price. So that the vibration of the main engine can be distributed evenly, then the construction characteristics in the connection area must be known so that the transmission can be engineered and resonance at a certain point can be avoided. Aim of this study is to analyze vibrations in the area of wooden ship construction with different excitation sources. The source of excitation comes from two different engines mounted on ships of the same size. The use of two different machines aims for the analysis to be able to recommend a connection that matches the performance of each machine through the amount of amplitude that occurs at the connection points. The results showed that the Dong Feng machine had the smallest amplitude value at $0.078 \mathrm{~mm}$ in the direction of the Tangential fiber, still above the allowable amplitude limit of $0.039 \mathrm{~mm}$ for the horizontal vibration direction. The amplitude generated from the use of the Dong Feng engine will be smaller if it uses a model III connection, a notched straight notch, with radial fiber direction, while the Yanmar engine will be better if it uses a model II connection with tangential fiber direction.
\end{abstract}

Keywords: characteristics of vibration, excitation, connection, resonance, amplitude. 


\section{PENDAHULUAN}

Getaran dari mesin dapat merusak konstruksi kapal [1] jika tidak diperhitungkan kemampuannya dalam menerima beban dinamis. Penentuan sumber getaran, adalah penting untuk menetapkan frekuensi eksitasi dan untuk menghubungkan frekuensi eksitasi dengan frekuensi rotasi poros, dengan menentukan jumlah osilasi per revolusi poros [2]. Faktor keselamatan, keandalan dan kontrol kualitas menjadi hal yang sangat penting untuk dipertimbangkan dan tidak dapat dihindari. Karena itu, perlu dilakukan pengembangan teknik analisis dan teknologi pengukuran karakterisasi material [3].

Salah satu karakteristik suatu material yang penting adalah nilai kekakuannya ([1], [4]). Peningkatan kekakuan suatu struktur akan berpengaruh terhadap distribusi getaran yang terjadi terhadap suatu sistem.

Pada kapal kayu, beban dinamis dan statik dialami secara bersamaan. Ref. [5] telah melakukan analisa mengenai sambungan dan pengancingan pada konstruksi bangunan kayu. Sedangkan analisis getaran pada pondasi mesin di kapal kayu telah dilakukan oleh [6], dengan melakukan eksperimen dimana ukuran kanal pondasi tidak dirubah hanya nilai c yang di variasi.

Peredam karet dengan ketebalan hasil perhitungan dipasang pada pondasi kapal kayu dan analisa titik pengancingan pondasi ke balok pondasi 2, 3 dan 4 titik [7] untuk memperbaiki distribusi beban akibat getaran mesin ke struktur. Perbaikan sambungan pada kayu mempunyai pengaruh pada nilai kekakuan sistem pengikatan dikarenakan sifat mekaniknya seperti dilakukan oleh [8]. Karakteristik getaran akibat pengaruh model sambungan, alat sambung dan arah serat juga telah diteliti oleh [9]. Mesin yang digunakan memiliki andil dalam mengurangi besar amplitude yang terjadi pada kapal. Sumber eksitasi dua mesin dibandingkan, dimana jenis sambungan kayu bergantung pada besarnya amplitude yang terjadi dan titik-titik kritis.

Karakteristik getaran menolong dalam upaya mengurangi dampak buruk getaran yang terjadi terhadap kekuatan struktur. Penelitian ini memperhatikan daerah kritis dimana titik resonansi dapat dihindari jika diketahui besarnya eksitasi dari sumber getar.

\section{BAHAN DAN METODE 2.1. Material Penelitian}

Material yang digunakan adalah kayu lokal dengan mesin yang digunakan adalah mesin Dong Feng dan Yanmar.

\subsection{Experimental Modal Analysis}

Modal frekuensi adalah frekuensi puncak pada curve fitting, sedangkan Modal damping diperoleh dari lebar half power bandwith. Mode shape diperoleh dari hasil simulasi dengan menggunakan 2 mesin yang berbeda.

\subsection{Karakteristik Getaran Berdasarkan Hasil Simulasi}

Proses simulasi dilakukan pada konstruksi kamar mesin kapal kayu dengan sumber eksitasi berasal dari mesin Dong Feng dan Yanmar. Hasil simulasi berupa tabel data, grafik, animasi 3D dan distribusi beban dinamis pada konstruksi kapal kayu. Data dimasukkan secara manual yang memperlihatkan distribusi beban dan daerah kritisnya. Tingkat akurasi bergantung pada ukuran meshing. Semakin kecil meshing akan menambah waktu tunggu proses analisis/ solution yang memakan waktu beberapa hari. Semakin kecil ukuran meshing maka tingkat akurasi semakin tinggi. Grafik dan tabel digunakan untuk mempermudah dalam proses analisa daerah kritis.

\section{HASIL DAN PEMBAHASAN}

\subsection{Proses Rekomendasi Model Simulasi Ka mar Mesin Kapal Kayu}

Model simulasi yang dibuat berdasarkan variasi arah serat, alat sambung dan model sambungan. Model simulasi yang direkomendasikan ada 2 model yaitu dari arah serat Radial dan Tangensial.

\subsection{Rekomendasi Model Simulasi dalam Arah Serat Radial}

Berdasarkan hasil analisis parameter getaran maka model takik lurus alat sambung paku terbaik untuk arah serat Radial. Pada model ini amplitude yang terjadi sebesar $0,0349 \mathrm{~mm}$ terkecil dibandingkan dengan nilai amplitude pada model dan alat sambung lainnya. 
$\underline{\text { Tabel 1. Parameter getaran arah serat radial }}$

\begin{tabular}{|c|c|c|c|c|c|c|c|c|c|c|}
\hline \multirow{3}{*}{$\begin{array}{c}\text { Alat } \\
\text { Sambung }\end{array}$} & \multirow{3}{*}{ Model } & \multicolumn{9}{|c|}{ Horisontal } \\
\hline & & \multicolumn{9}{|c|}{ Radial } \\
\hline & & $\omega_{0}(H z)$ & $\%$ & $\mathrm{a}(\mathrm{mm} / \mathrm{N})$ & $\mathrm{k}(\mathrm{N} / \mathrm{mm})$ & $x$ & $\%$ & $F_{T R}(\mathrm{~N})$ & TR & $\%$ \\
\hline \multirow{4}{*}{ Baut } & I & 41.9 & $53.7 \%$ & 3.76.E-05 & $2.66 \mathrm{E}+04$ & 0.024 & $35.0 \%$ & 16949 & 0.976 & $1.3 \%$ \\
\hline & II & 37.2 & $36.6 \%$ & 6.58.E-06 & $1.52 \mathrm{E}+05$ & 0.027 & $26.8 \%$ & 16897 & 0.973 & $1.0 \%$ \\
\hline & III & 40.7 & $49.2 \%$ & 3.13.E-05 & $3.20 \mathrm{E}+04$ & 0.025 & $33.0 \%$ & 16937 & 0.975 & $1.3 \%$ \\
\hline & IV & 40.9 & $50.0 \%$ & 1.16.E-05 & $8.63 \mathrm{E}+04$ & 0.024 & $33.3 \%$ & 16939 & 0.976 & $1.3 \%$ \\
\hline \multirow{4}{*}{ Paku } & I & 39.7 & $45.5 \%$ & 1.09.E-05 & $9.20 \mathrm{E}+04$ & 0.025 & $31.3 \%$ & 16926 & 0.975 & $1.2 \%$ \\
\hline & II & 39.4 & $44.7 \%$ & 9.01.E-06 & $1.11 \mathrm{E}+05$ & 0.025 & $30.9 \%$ & 16923 & 0.975 & $1.2 \%$ \\
\hline & III & 39.4 & $44.5 \%$ & 4.02.E-06 & $2.49 \mathrm{E}+05$ & 0.025 & $30.8 \%$ & 16923 & 0.975 & $1.2 \%$ \\
\hline & IV & 39.1 & $43.5 \%$ & 1.87.E-05 & $5.36 \mathrm{E}+04$ & 0.026 & $30.3 \%$ & 16920 & 0.974 & $1.2 \%$ \\
\hline \multirow{4}{*}{ Pasak } & I & 35.5 & $30.1 \%$ & 3.23.E-05 & $3.10 \mathrm{E}+04$ & 0.028 & $23.1 \%$ & 16874 & 0.972 & $0.9 \%$ \\
\hline & II & 35.9 & $31.6 \%$ & 1.87.E-05 & $5.36 \mathrm{E}+04$ & 0.028 & $24.0 \%$ & 16880 & 0.972 & $0.9 \%$ \\
\hline & III & 34.0 & $24.8 \%$ & 5.15.E-04 & $1.94 \mathrm{E}+03$ & 0.029 & $19.9 \%$ & 16853 & 0.971 & $0.8 \%$ \\
\hline & IV & 34.5 & $26.5 \%$ & 1.42.E-05 & $7.05 E+04$ & 0.029 & $21.0 \%$ & 16860 & 0.971 & $0.8 \%$ \\
\hline $\begin{array}{c}\text { Tanpa } \\
\text { sambungan }\end{array}$ & & 27.3 & & 3.06.E-05 & 3.06E-05 & 0.037 & & 5727 & 0.963 & \\
\hline
\end{tabular}

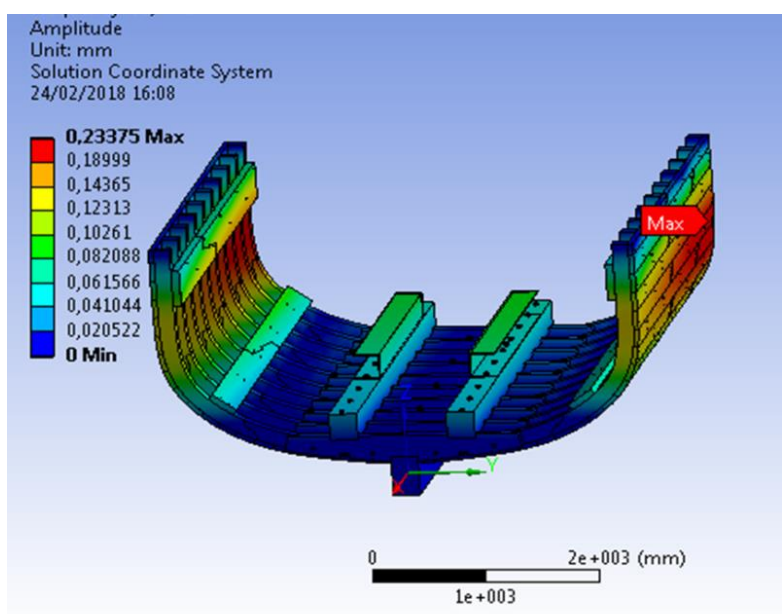

Gambar 1. Response struktur model III takik lurus menggunakan alat sambung paku arah serat radial dan deformasi horisontal (Mesin Yanmar)

Sebagai pembanding hasil response sruktur akibat eksitasi mesin Yanmar maka dilakukan simulasi untuk model yang direkomendasikan pada bagian yang sama. Mesin pembanding yang digunakan yaitu mesin Dong Feng. Berdasarkan hasil analisis parameter getaran maka pada model simulasi menggunakan mesin Dong Feng amplitude yang terjadi sebesar $0,05117 \mathrm{~mm}$ terkecil dibandingkan dengan nilai amplitude pada model dan alat sambung lainnya. Perbandingan nilai amplitude dapat dilihat pada Gambar 3. Rasio transmisi pada mesin Dong Feng kurang dari 1 yang artinya struktur memerlukan isolasi tambahan.

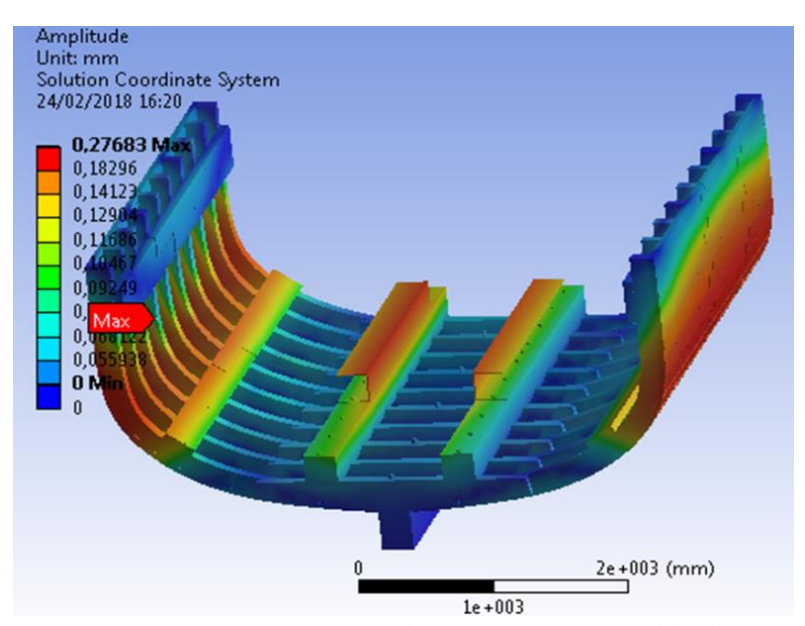

Gambar 2. Response struktur model III takik lurus menggunakan alat sambung paku arah serat radial dan deformasi horisontal (Mesin Dong Feng)

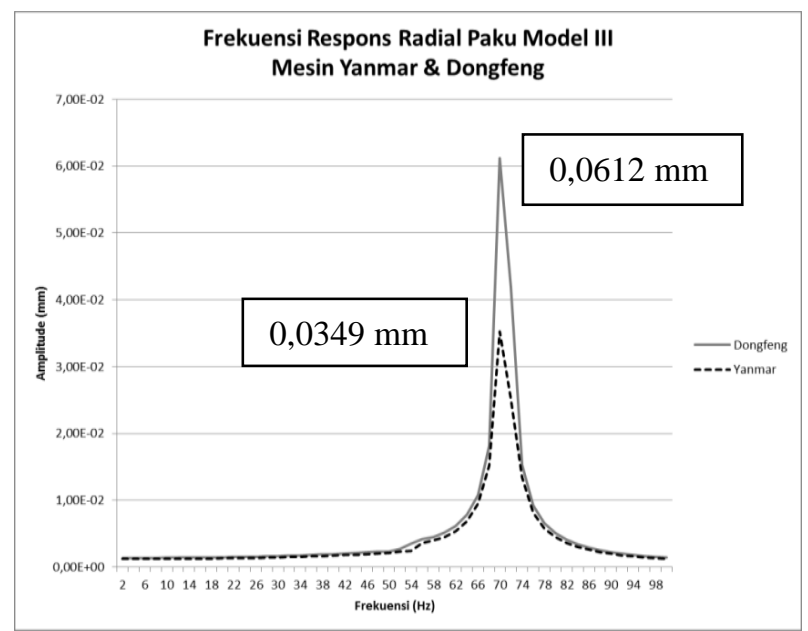


Gambar 3. Grafik frekuensi response struktur model III takik lurus menggunakan alat sambung paku arah serat radial dan deformasi horisontal

Tabel 2. Parameter getaran arah serat tangensial

\begin{tabular}{|c|c|c|c|c|c|c|c|c|c|c|}
\hline \multirow[t]{3}{*}{$\begin{array}{c}\text { Alat } \\
\text { Sambung }\end{array}$} & \multirow[t]{3}{*}{ Model } & \multicolumn{9}{|c|}{ Horisontal } \\
\hline & & \multicolumn{9}{|c|}{ Tangensial } \\
\hline & & $\omega O_{(\mathrm{Hz})}$ & $\%$ & $\mathrm{a}(\mathrm{mm} / \mathrm{N})$ & $\mathrm{k}(\mathrm{N} / \mathrm{mm})$ & $x$ & $\%$ & $F T R(\mathrm{~N})$ & TR & $\%$ \\
\hline \multirow{4}{*}{ Baut } & I & 48.4 & $32.8 \%$ & 1.30.E-05 & $7.72 \mathrm{E}+04$ & 0.021 & $24.7 \%$ & 17005 & 0.979 & $0.7 \%$ \\
\hline & II & 48.3 & $32.6 \%$ & 1.66.E-05 & $6.04 \mathrm{E}+04$ & 0.021 & $24.6 \%$ & 17004 & 0.979 & $0.7 \%$ \\
\hline & III & 50.9 & $39.5 \%$ & 5.52.E-05 & $1.81 \mathrm{E}+04$ & 0.020 & $28.3 \%$ & 17022 & 0.980 & $0.8 \%$ \\
\hline & IV & 47.2 & $29.4 \%$ & 1.01.E-05 & $9.95 \mathrm{E}+04$ & 0.021 & $22.7 \%$ & 16996 & 0.979 & $0.6 \%$ \\
\hline \multirow{4}{*}{ Paku } & I & 50.8 & $39.2 \%$ & 5.92.E-05 & $1.69 \mathrm{E}+04$ & 0.020 & $28.2 \%$ & 17022 & 0.980 & $0.8 \%$ \\
\hline & II & 50.7 & $39.1 \%$ & 1.40.E-04 & $7.13 \mathrm{E}+03$ & 0.020 & $28.1 \%$ & 17021 & 0.980 & $0.8 \%$ \\
\hline & III & 50.7 & $39.1 \%$ & 1.71.E-04 & $5.84 \mathrm{E}+03$ & 0.020 & $28.1 \%$ & 17021 & 0.980 & $0.8 \%$ \\
\hline & IV & 50.0 & $37.1 \%$ & 8.47.E-05 & $1.18 \mathrm{E}+04$ & 0.020 & $27.1 \%$ & 17016 & 0.980 & $0.8 \%$ \\
\hline \multirow{4}{*}{ Pasak } & I & 41.2 & $12.9 \%$ & 5.26.E-05 & $1.90 \mathrm{E}+04$ & 0.024 & $11.4 \%$ & 16942 & 0.976 & $0.3 \%$ \\
\hline & II & 38.0 & $4.3 \%$ & 2.02.E-06 & $4.95 \mathrm{E}+05$ & 0.026 & $4.2 \%$ & 16907 & 0.974 & $0.1 \%$ \\
\hline & III & 38.4 & $5.4 \%$ & 4.12.E-05 & $2.43 \mathrm{E}+04$ & 0.026 & $5.2 \%$ & 16912 & 0.974 & $0.1 \%$ \\
\hline & IV & 38.4 & $5.4 \%$ & 5.65.E-06 & $1.77 \mathrm{E}+05$ & 0.026 & $5.1 \%$ & 16912 & 0.974 & $0.1 \%$ \\
\hline No Joint & & 36.5 & & 4.35.E-06 & $2.30 \mathrm{E}+05$ & 0.027 & & 16887 & 0.973 & \\
\hline
\end{tabular}

\subsection{Rekomendasi Model Simulasi dalam Arah Serat Tangensial}

Berdasarkan hasil analisis parameter getaran maka model II (takik lurus berkait) alat sambung pasak terbaik untuk arah serat Tangensial. Pada model ini amplitude yang terjadi sebesar $0,0175 \mathrm{~mm}$, merupakan yang terkecil bila dibandingkan dengan nilai amplitude pada model dan alat sambung lainnya.

Perbandingan antara arah serat radial dan tangensial dapat dilihat pada Gambar 2 dan Gambar 4 yang menunjukkan bahwa model dengan arah serat tangensial memiliki lebih sedikit area kritis dari model dengan menggunakan arah serat radial.

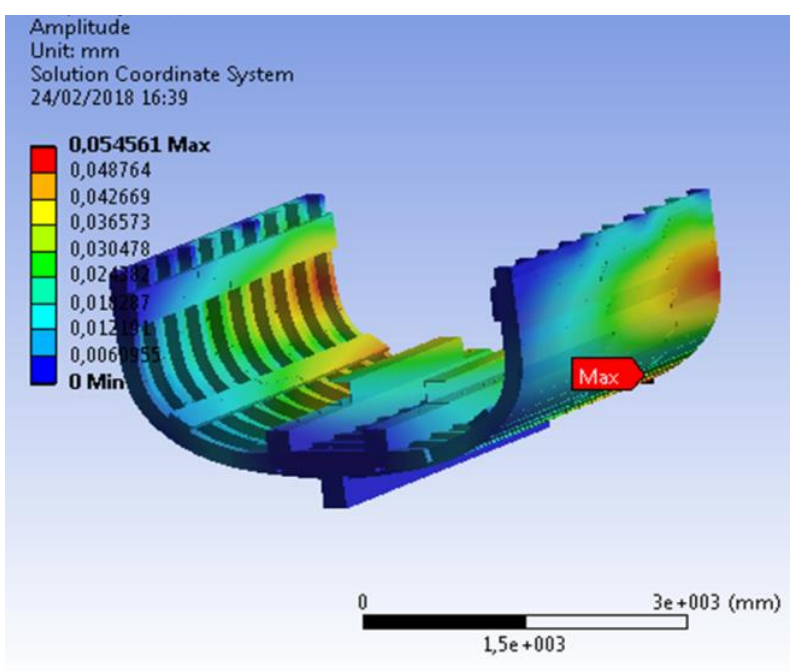

Gambar 4. Response struktur model II takik miring berkait menggunakan alat sambung pasak arah serat tangensial dan deformasi horisontal

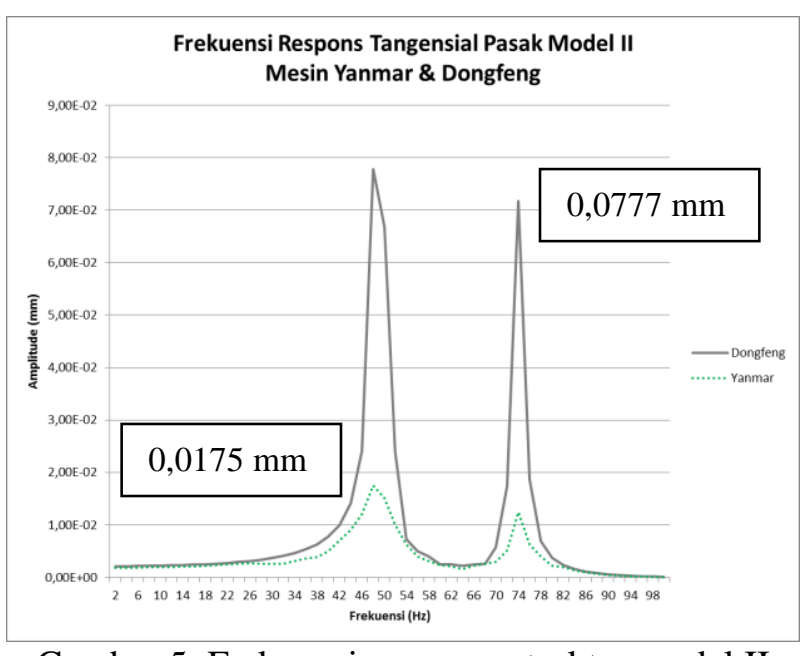

Gambar 5. Frekuensi response struktur model II takik miring berkait menggunakan alat sambung pasak arah serat tangensial dan deformasi horisontal

Sebagai pembanding hasil response struktur akibat eksitasi mesin Yanmar maka dilakukan simulasi untuk model yang direkomendasikan pada bagian yang sama. Mesin pembanding yang digunakan yaitu mesin Dong Feng. Berdasarkan hasil analisis parameter getaran maka pada model simulasi menggunakan mesin Dong Feng amplitude 
yang terjadi sebesar $0,0777 \mathrm{~mm}$. Getaran yang terjadi menjadi cukup besar, perbandingan menggunakan dua mesin berbeda dapat dilihat pada Gambar 5. Mesin Dong Feng memiliki nilai amplitude yang besar dibandingkan mesin Yanmar. Harga mesin Dong Feng yang murah menguntungkan dari segi ekonomis tetapi menjadi pilihan yang buruk dari sisi teknis. Rekomendasi yang dibuat untuk kondisi ini adalah jika mesin yang digunakan Dong Feng maka arah serat yang tepat yaitu R model III takik lurus alat sambung paku dan untuk mesin Yanmar adalah arah serat $\mathrm{T}$ model II takik miring berkait alat sambung pasak.

\section{KESIMPULAN}

Getaran pada kapal kayu tradisional dapat diminimalisir dengan melakukan pemilihan jenis sambungan yang sesuai dengan karakter mesin. Mesin dengan getaran yang besar di frekuensi rendah akan menghasilkan amplitude yang besar pula. Pada penelitian ini mesin Dong Feng memiliki nilai amplitude terkecil masih di $0,078 \mathrm{~mm}$ pada arah serat $\mathrm{T}$ di atas batas amplitude yang diijinkan yaitu $0,039 \mathrm{~mm}$ untuk arah getaran horisontal. Amplitude yang dihasilkan akibat penggunaan mesin Dong Feng akan lebih kecil jika menggunakan model III takik lurus, arah serat Radial sedangkan mesin Yanmar akan lebih baik jika menggunakan model II takik miring berkait, arah serat Tangensial

\section{UCAPAN TERIMA KASIH}

Penelitian ini terlaksana atas bantuan Dana Penelitian yang berasal dari PNBP Fakultas Teknik tahun 2019. Untuk itu, penulis menyampaikan terima kasih kepada Pimpinan Fakultas Teknik Universitas Pattimura.

\section{DAFTAR PUSTAKA}

[1] T. R. Lin, J. Pan, P. J. O'Shea, and C. K. Mechefske, "A study of vibration and vibration control of ship structures," Mar. Struct., vol. 22, no. 4, pp. 730-743, Oct. 2009, doi: 10.1016/j.marstruc.2009.06.004.

[2] A. Yucel and A. Arpaci, "Free and forced vibration analyses of ship structures using the finite element method," J. Mar. Sci. Technol., vol. 18, no. 3, pp. 324-338, Sep. 2013, doi: 10.1007/s00773-012-0210-1.

[3] M. H. M. A. Tan, N. L. T. Lile, F. Mat, and S. Yaacob, "Characterization of Materials by Vibration Technique," IIUM Eng. J., vol. 12, no. 3, Dec. 2011, Accessed: Sep. 26, 2018. [Online]. Available: http://journals.iium.edu.my/ejournal/index.php/ iiumej/article/view/143.

[4] O. Soegihardjo and Suhardjono, "Simulasi untuk Memprediksi Pengaruh Stiffener pada Peningkatan Kekakuan Benda Kerja," J. Tek. Mesin, vol. 14, no. 1, pp. 40-46, Sep. 2013, doi: $10.9744 / \mathrm{jtm} .14 .1 .40-46$.

[5] R. J. M. Craik and L. Galbrun, "Vibration transmission through a frame typical of timberframed buildings," J. Sound Vib., vol. 281, no. 3, pp. 763-782, Mar. 2005, doi: 10.1016/j.jsv.2004.02.015.

[6] D. R. Lekatompessy, "Tinjauan Pengaruh Getaran Mesin Terpasang Terhadap Kekuatan Konstruksi Pondasi Kapal Tradisional," J. Teknol., vol. 2, no. 1, pp. 27-35, 2005.

[7] D. R. Lekatompessy, O. O. Sulaiman, F. Manuhutu, E. J. De Lima, and M. Manuputty, "Rubber as an Effective Vibration Absorber of Outboard Engine at Small Traditional Fishing Boats from the Human Health and Safety Point of View," J. Eng. Comput. Appl. Sci., vol. 2, no. 2, pp. 7-12, Feb. 2013.

[8] D. R. Lekatompessy, I. M. Ariana, A. Zubaydi, and E. Erwandi, "The Vibration Characteristics of Gofasa Wood (vitex cofassus)," Int. Rev. Mech. Eng. IREME, vol. 11, no. 9, pp. 644650, Sep. 2017, doi: 10.15866/ireme.v11i9.11636.

[9] D. R. Lekatompessy, I. M. Ariana, A. Zubaydi, and E. Erwandi, "The Effect of the Fiber of Wood and Connection Tools on the Vibration Characteristics of Gofasa Wood (Vitex cofassus)," Res. J. Appl. Sci. Eng. Technol., vol. 14, no. 7, pp. 242-250, Jul. 2017, doi: DOI:10.19026/rjaset.14.4786. 